\title{
Biodiesel Production from Jatropha Seeds
}

\author{
Ghada Ahmed Kadry \\ Chemical Engineering Department, High Institute of Engineering, El-Shorouk Academy, Cairo, Egypt
}

\section{Email address:}

kadryghada@Yahoo.com

\section{To cite this article:}

Ghada Ahmed kadry. Biodiesel Production from Jatropha Seeds. American Journal of Chemical Engineering. Vol. 3, No. 6, 2015 , pp. 89-98. doi: 10.11648/j.ajche.20150306.13

\begin{abstract}
This work was performed to extract oil from Jatropha seeds and to study the optimum conditions of extraction. The extraction process was observed with regard to oil yield percent versus time to calculate the kinetic and thermodynamic parameter. On the other hand, Jatropha oil was used as feed stock for biodiesel production by alkali catalyzed methanolysis. The optimum condition for the production process was studied depending on the methyl ester content. The Jatropha biodiesel was blended with 10,15 , and $25 \%$ with petroleum diesel and the thermo-physical properties were studied. All the measured properties of Jatropha oil and biodiesel are determined by international standards ASTM6751-07b, with exception of lower oxidation stability.
\end{abstract}

Keywords: Jatropha Seed, Extraction, Thermodynamics Study, Kinetic Study, Transesterification, Biodiesel, Blend Biodiesel

\section{Introduction}

Biodiesel is defined as the monoalkyl esters of fatty acids derived from vegetable oils or animal fats. In simple terms, biodiesel is the product you get when a vegetable oil or animal fat is chemically reacted with an alcohol to produce a fatty acid alkyl ester [1-2].

A catalyst such as sodium or potassium hydroxide is required [2-3].

Glycerol is produced as a byproduct. Biodiesel is manufactured from plant oils, animal fats and recycled cooking oils [4]. Bio-diesel contains no petroleum, but it can be blended at any level with petroleum diesel to create a biodiesel blend or can be used in its pure form. Just like petroleum diesel, biodiesel operates in compression ignition (diesel) engine; which essentially require very little or no engine modifications because biodiesel has properties similar to petroleum diesel fuels [5]. It can be stored just like the petroleum diesel fuel and hence, does not require separate infrastructure. Biodiesel is considered clean fuel since it has almost no sulphur, no aromatics and has about $10 \%$ built-in oxygen, which helps it to burn fully [6-7]. Its higher cetane number improves the ignition quality even when blended in the petroleum diesel. As countries grow and become more industrialized, their energy needs grow with them. One of the most readily available and economical sources of energy is fossil fuels [8]. While abundant and inexpensive, fossil fuels are a finite source of energy that some estimates state will last only 40 more years. In addition, combustion of fossil fuels produces harmful pollutants that are exhausted into the atmosphere. Many of these pollutants contribute to detrimental phenomenon such as acid rain and health problems which are caused respectively by an increased amount of sulfur emissions and among Production. Although, global climate change from increased green house gas emissions remains one of the most prominent debatable issues today, the concentration of $\mathrm{CO}_{2}$ in the atmosphere has almost doubled in the last 60 years. The present study is aimed of extracting oil from Jatropha seeds using Isopropanol, petroleum ether and n-hexane investigating the effects of temperature, time, solvent to solid (volume of solvent) and particle size on the percentage of yield of oil and determines the kinetics and thermodynamic parameters of the oil extraction from Jatropha seeds. Then study the production of biodiesel by transesterification using alkali catalyzed process. The optimum conditions of production were studied. These variables include methanol: oil molar ratio of 4:1, 6:1, $8: 1,10: 1$, catalyst concentration of $0.5 \%, 1 \%, 2 \% \mathrm{w} / \mathrm{w}$ of oil , reaction temperature of $32^{\circ}, 45^{\circ}$ and $60^{\circ} \mathrm{C}$, and reaction times of 10,20,30,40 min. the methyl ester content in the product for the maximum yield was analyzed by gas chromatography (GC). The Jatropha biodiesel blends with 10,15 and $25 \%$ with diesel petroleum fuel and the thermophysical properties were studied. 


\section{Experimental Technique}

\subsection{Materials}

Jatropha seeds have been delivered from local market for ministry of agriculture in Egypt, Cairo for the extraction process. The seeds were shelled, and ground to a mesh size $0.5 \mathrm{~cm}$. The moisture content of the ground Jatropha seeds was $0.912 \%$. Hexane, Isopropanol, Petroleum ether, $\mathrm{NaOH}$ and ethanol are analytical grade.

\subsection{Extraction of Oil}

Extraction of Jatropha oil from seeds was optimized using organic solvent based on the amount of the extracted oil and these experiments has been affected by type of organic solvent, temperature, particle size of seeds ,equipment used in extraction and time of extraction.

\subsubsection{Experimental Procedure}

Jatropha seeds were cracked and the shells were carefully removed. The kernels were ground and sieved by using 0.5 and $0.75 \mathrm{~cm}$ sieve plates. The seeds were categorized into two particle size classes: below $0.5 \mathrm{~cm}$, and $0.5 \mathrm{~cm}$. Then put in oven for $1 \mathrm{hr}$. at $100^{\circ} \mathrm{C}$ and the moisture content was determine.

\subsubsection{Optimization of Oil Extraction from Jatropha Seeds}

The effect of solvent, temperature, solvent to solid ratio, particle size of the meal and reaction time were investigated to optimize the extraction operating conditions for achieving maximum oil yield [9].

$10 \mathrm{gm}$ of grinded meal with $60 \mathrm{ml}$ of three types of solvent namely $\mathrm{n}$-hexane, Isopropanol and petroleum ether. The extraction temperature was varied from room temperature $\left(25^{\circ} \mathrm{C}\right)$ to boiling point of the solvent while the total extraction time is $2 \mathrm{hr}$. and seed size was below 0.5 , and over $0.5 \mathrm{~cm}$. These parameters were varied one at a time to identify the optimum conditions for each type of solvent. At the end of the extraction, the micelle was filtered to remove suspended solids. Subsequently, the solvent was separated from the oil using rotary vacuum evaporator (Laborota 4000) and was collected in the receiving flask. The oil which was remained in the sample flask was weighed after the process was completed. The percentage of extracted oil was calculated by dividing the amount of obtained oil by the amount of the seeds multiply by 100 . All experiments were repeated twice at least. The percentage oil yield was calculated using the expression below:

$$
\text { Yield } \%=\frac{\text { weight of pure oil extracted }(\mathrm{gm})}{\text { wt of seed sample }(\mathrm{gm})} \times 100
$$

\subsection{Kinetics and Thermodynamic of Extraction Jatropha Oil}

Based on the optimum parameters achieved from the optimization process, the rate of extraction of Jatropha oil was determined at different temperatures where the heating mental is set at a specified temperature $70^{\circ} \mathrm{C}, 80^{\circ} \mathrm{C}, 90^{\circ} \mathrm{C}$, $100^{\circ} \mathrm{C}$ and $110^{\circ} \mathrm{C}$. The extraction was carried out in six extraction cycles of $10 \mathrm{~min}-1 \mathrm{~h}$. In each cycle, $45 \mathrm{~g}$ below 0.5 particle size seeds were extracted using hexane in Soxhlet extractor. At the end of each cycle, the set up (Soxhlet extractor) was dismantled and the miscella (mixture of nhexane and Jatropha seed oil) obtained was poured into the distillation flask and placed on the heating mantle. The heating mantle was set at $68^{\circ} \mathrm{C}$ which is the boiling point of pure hexane. After distillation, the weight of the oil was determined. The experiment was repeated at $\left(110^{\circ} \mathrm{C}\right)$ for $(11$ hr.) to get max. yield. Kinetic studies measure the speed or rate of a chemical extraction reaction. The power model equation [10-14] is given as:

$$
\frac{d Y}{d t}=k Y^{n}
$$

Equation (2) can be expressed as

$$
\operatorname{In} \frac{\mathrm{dY}}{\mathrm{dt}}=\mathrm{n} \operatorname{In} Y+\operatorname{In} K
$$

where, $\mathrm{Y}$ is percentage oil yield, $\mathrm{t}$ is time of extraction $(\mathrm{min}), \mathrm{K}$ is extraction constant and $\mathrm{n}$ is reaction order. A plot of $\ln (\mathrm{d} Y / \mathrm{dt})$ against $\ln \mathrm{Y}$ gives $\operatorname{lnk}$ as intercept and $\mathrm{n}$ as the slope Thermodynamics parameters are determined from equation 4 .

$$
\text { In } \mathrm{k}=\frac{-\Delta \mathrm{G}}{\mathrm{RT}}=\frac{-\Delta \mathrm{H}}{\mathrm{RT}}+\frac{\Delta \mathrm{S}}{\mathrm{R}}
$$

Where, $\mathrm{k}$ is equilibrium constant, $\Delta \mathrm{G}$ is Gibbs energy or free energy $(\mathrm{KJ} / \mathrm{mol}), \Delta \mathrm{H}$ is change of enthalpy $(\mathrm{KJ} / \mathrm{mol}), \Delta \mathrm{S}$ is change in entropy $(\mathrm{KJ} / \mathrm{mol} . \mathrm{K}), \mathrm{R}$ is Universal gas constant $(8.314 \mathrm{KJ} / \mathrm{Kmol}), \mathrm{T}$ is the temperature $(\mathrm{K})$ and

$$
K=\frac{\mathrm{Y}_{\mathrm{T}}}{\mathrm{Y}_{\mathrm{U}}}
$$

Where, $\mathrm{Y}_{\mathrm{T}}=$ Percentage oil yield at temperature, $\mathrm{T}$ and $\mathrm{Y}_{\mathrm{u}}=$ Percentage of unextracted oil. Plotting lnk against $1 / \mathrm{T}$ gives $-\Delta \mathrm{H} / \mathrm{R}$ as slope and $\Delta \mathrm{S} / \mathrm{R}$ as intercept, from where $\Delta \mathrm{H}, \Delta \mathrm{S}$ a nd $\Delta \mathrm{G}$ was determined.

Calculation of Activation Energy:

The activation energy can be calculated from e Arrhenius Equation (6):

$$
\mathrm{k}=\mathrm{Ae}^{-\mathrm{Ea} / \mathrm{RT}}
$$

Where $\mathrm{k}$ is the extraction rate constant, $\mathrm{A}$ is the Arrhenius constant or frequency factor, Ea. is the activation energy, $\mathrm{R}$ is the universal gas constant, and $\mathrm{T}$ is the absolute temperature. A plot of lnk vs. 1/T gives a straight line whose slope represents the activation energy of extraction, - Ea. / R, and whose intercept is the Arrhenius constant.

\subsection{Characterization of the Extracted Jatropha Seed Oil}

The oil was characterized for physical and chemical properties such as acid value, fatty acid, saponification value, specific gravity, viscosity and moisture content. 


\subsubsection{Acid Value Determination}

This is the number of milligram of $\mathrm{KOH}$ required to neutralize the free fatty acid in $1 \mathrm{~g}$ of sample. $5 \mathrm{gm}$ of oil sample was dissolved in $25 \mathrm{ml}$ fat solvent $(95 \%$ ethanol: ether) (1:1 volume\%) then titrated with $0.1 \mathrm{~N} \mathrm{KOH}$ using ph.ph as indicator until permanent pink color was appeared. The experiment was prepared for blank study. The acid value was calculated according to the following formula:

$$
\text { Acid value }=\frac{\text { Titre value } * \text { Normality of } \mathrm{KOH} * 56.1}{\text { wt of oil sample }} \times 100
$$

\subsubsection{Moisture Content Determination}

The moisture content of raw oil was determined using oven drying method $5 \mathrm{gm}$ of Jatropha oil was weighed then dried in electrical oven at $\left(130^{\circ} \mathrm{C}\right.$ for $1 \mathrm{hr}$.)

$$
\text { Moisture content }=\frac{\text { Wt of wet oil-wt of dry oil }}{\text { wt of oil sample }} \times 100
$$

\subsubsection{Specific Gravity Determination}

The specific gravity of raw oil was determined using density bottle method.

The clean dried density bottle of $25 \mathrm{ml}$ capacity was weighed. Then fitted with water then stop and was reweighed. Then Fitted with oil then stopped and reweighed.

$$
\text { Specific gravity }=\frac{\text { mass of oil }}{\text { mass of equal volume of water }}
$$

\subsubsection{Saponification Value Determination}

This is milligram of $\mathrm{KOH}$ required to saponify $1 \mathrm{~g}$ of fat or oil. Saponification value is measure of the molecular weight of fatty acid. the AOCS method Cd 3-25 was employed. 2 gm of oil sample was heated with $50 \mathrm{~cm}^{3}$ of $0.5 \mathrm{M}$ Methanolic $\mathrm{KOH}$ more than $1 \mathrm{hr}$ "until alkaline hydrolysis was occurred ". Then titrated with $0.5 \mathrm{~N} \mathrm{HCl}$ using ph.ph. Indicator until permanent pink color was appeared the experiment was prepared for blank study. The saponification value was calculated using the formula:

$$
\text { Saponification value }=\frac{\text { Titer value } * \text { Normality of } \mathrm{KOH} * 56.1}{\text { wt of oil sample }}
$$

\subsubsection{Percentage of Fatty Acid Determination}

This is the percentage by weight of specified fatty acid in the oil. The method applied for this analysis, is the American oil chemists Society (AOCS) method 5a-40. $1 \mathrm{~g}$ of sample was measured in a conical flask and dissolve with $25 \mathrm{ml}$ of isopropyl alcohol .3drops of phenolphthalein indicator was added to solution. the mixture was titrated with $0.1 \mathrm{~N} \mathrm{NaOH}$ solution shaken constantly until a pink colour persisted for 30 $\mathrm{s}$ the percentage FFA was then calculated using the formula:

$$
\% \mathrm{FFA}=\frac{\text { Titer value } * \text { Normality of } \mathrm{NaOH} * 28.2}{\text { Wt of oil sample }}
$$

\subsubsection{Viscosity Determination}

The viscosity was determined by using spindle No.2 of rotary digital viscometer.

\subsubsection{Chemical Composition}

Jatropha oil used for production of biodiesel was generously offered by the National Research Center, Egypt. Fatty acids composition of the used Jatropha and the molecular weight were determined by the National Research Center, Egypt using gas liquid chromatographic analysis of the oil. The chromatographic analysis was made using Hewlett Packard Model 6890 chromatograph.

\subsection{Production of Biodiesel by Transesterification}

\subsubsection{Oil Pre-treatment}

The oil extracted contain water and some solid particle, it was heated at a temperature of $130^{\circ} \mathrm{C}$ for $30 \mathrm{~min}$ to boil out the water [15], it was then allowed to cool and settle over night and filtrated to remove the solid particles. The removal of water from oil is necessary because water content of above $0.5 \%$ facilitate saponification.

\subsubsection{Oil Transesterification}

The crude Jatropha oil, methanol, and sodium hydroxide were used in amounts established for each experiment. Since the FFA $\%$ is less than $1 \%$, so no need for reduction step [16]. The oil was initially charged into the reactor, and then preheated to the desired temperature. In order to maintain the catalytic activity, the solution of sodium hydroxide in methanol was freshly prepared so that prolonged contact with the air would not diminish the effectiveness of the catalyst through interaction with moisture and carbon dioxide. The catalyst solution was added to the preheated oil after which the reaction was timed. After the reaction, the mixture was allowed to settle under gravity for 24 hours in the separator funnel. Two layers were formed: the upper layer consisted of methyl ester, methanol traces, residual catalyst, and other impurities, whereas the lower layer consisted of glycerin, excess methanol, catalyst, and other impurities. After separation from the glycerin layer, the methyl ester layer was purified by washing with hot distilled water at $60^{\circ} \mathrm{C}$ until the washing water had a $\mathrm{pH}$ value similar to that of distilled water. The hot distilled water-to-crude methyl ester ratio was 1:1. To prevent the possibility of losing the methyl ester due to emulsion formation, the washing was done gently. Next, any remaining water was removed from the methyl ester layer at $70^{\circ} \mathrm{C}$ by vacuum rotary evaporator.

\subsubsection{Optimizing the Transesterification Process}

Transesterification process was carried out on the oil with a view to establishing the optimum operating conditions for the biodiesel production. The variables optimized included reaction time, methanol -to -oil molar ratio, catalyst concentration and temperature.

\section{(i). Effects of Methanol-to-Oil Molar Ratio and Reaction Time}

The reaction was carried out by varying the methanol to oil molar ratio and the reaction time using a catalyst concentration of $1 \% \mathrm{w} / \mathrm{w}$ of oil and a reaction temperature of $60^{\circ} \mathrm{C}$ using $10 \mathrm{ml}$ of oil at different methanol to oil ratio $4: 1$, $6: 1,8: 1$, and 10:1 and at different reaction time 10, 20, 40, 60 $\min$. 


\section{(ii). Effects of Catalyst Concentration and Reaction Time}

In the present study, $\mathrm{NaOH}$ was chosen to catalyze the methanolysis due to its relatively low cost. The experiments were conducted with varying catalyst concentrations and reaction time using a methanol-to-oil molar ratio of $6: 1$ and a reaction temperature of $60^{\circ} \mathrm{C}$. At different catalyst concentrations to oil $0.5,1,2 \% \mathrm{wt} / \mathrm{wt}$

\section{(iii). Effects of Reaction Temperature}

The production of biodiesel from Jatropha oil was carried out at various reaction temperatures. The operating conditions were fixed at a methanol-to oil molar ratio of 10:1 and a catalyst concentration of $1 \% \mathrm{w} / \mathrm{w}$ of oil, reaction time was extended to $40 \mathrm{~min}$ at different temperatures 32,45 , $60^{\circ} \mathrm{C}$.

\section{(iv). Effects of Reaction Time}

The operation conditions of production of biodiesel were fixed at a methanol-to oil molar ratio of 10:1 and 12:1 and a catalyst concentration of $1 \% \mathrm{w} / \mathrm{w}$ of oil at fixed temperatures $60^{\circ} \mathrm{C}$ but the time variable from 10 to $70 \mathrm{~min}$.

\subsubsection{Product Analysis}

The biodiesel yield for each experiment is calculated .The optimum yield of $98 \%$ was selected and the tests were carried out to measure the biodiesel physical properties (specific gravity, viscosity, cetane number, flash point, cloud point and calorific value). Also these properties were measured in accordance with the standard methods to see if the biodiesel produced had comparable properties with ASTM D6751-02 standard B100.

\subsubsection{The Evaluation Study for the Blend Biodiesel Production}

After producing enough amount of biodiesel in lab a various sample of blend of biodiesel and diesel in different proportions $(10-15-25) \%$ were sent to the co-op for Petroleum Company for studying the thermo-physical properties and comparable with ASTM D6751-02 standard B100.

\section{Results and Discussion}

\subsection{Effect of Solvent}

Three different solvents were used to evaluate their extraction efficiency. The oil extraction capabilities of $\mathrm{n}$ hexane, Isopropanol and petroleum ether are shown in Fig. 1. The extraction yield with n- hexane was found to be about $10 \%$ more than that of petroleum ether and $20 \%$ than Isopropanol under similar condition.

\subsection{Effect of Particle Size}

The effect of particle size of meal on extraction yield is shown in Fig. 2. The extraction was carried out using two different meal sizes namely $0.5 \mathrm{~cm}$ and above. The highest percentage of oil yield was obtained from the $0.5 \mathrm{~cm}$ size particle which is $29.7 \%$ for $0.5 \mathrm{~cm}$ and $16.24 \%$ for particle size above than $0.5 \mathrm{~cm}$ using hexane as solvent at room temp.

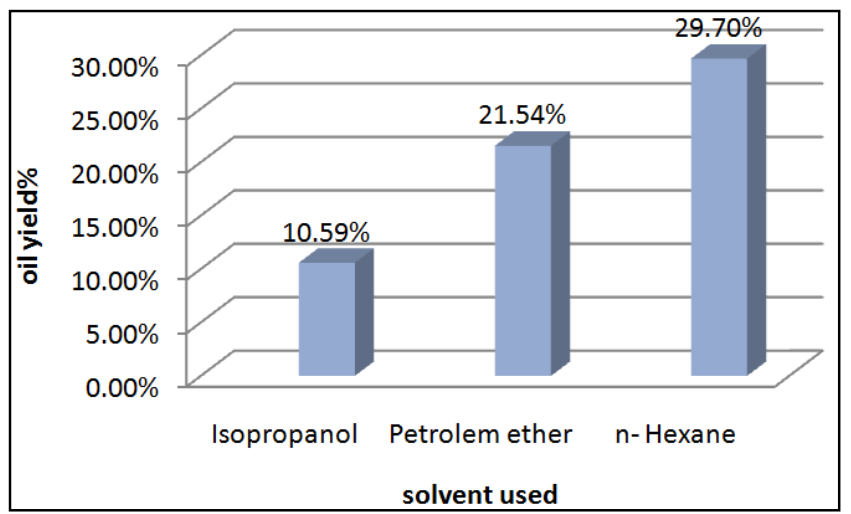

Fig. 1. The effect of three different solvents on the extraction efficiency at room temp. and particles size $0.5 \mathrm{~cm}$ for $2 \mathrm{hr}$.

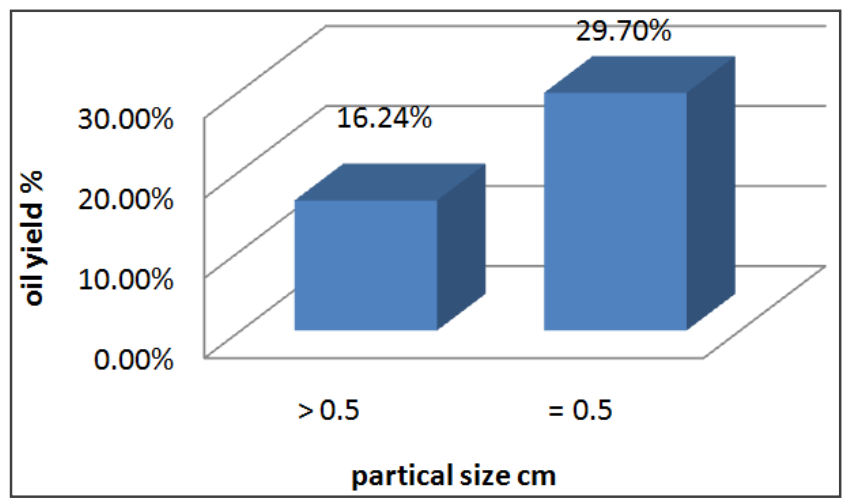

Fig. 2. The effect of seed size on amount of extracted oil, at room temp. for 2 $h r$.

\subsection{Effect of Extraction Temperature}

The effect of extraction temperature on the amount of extracted oil is shown in Fig. 3. When using hexane as the solvent, the amount of extracted oil increased around 5\% by increasing the extraction temperature from room temperature to 50 and from $45-60^{\circ} \mathrm{C}$. Extraction at boiling point (around $68^{\circ} \mathrm{C}$ ) gives about $40 \%$ of oil, $5 \%$ higher than at $50^{\circ} \mathrm{C}$.

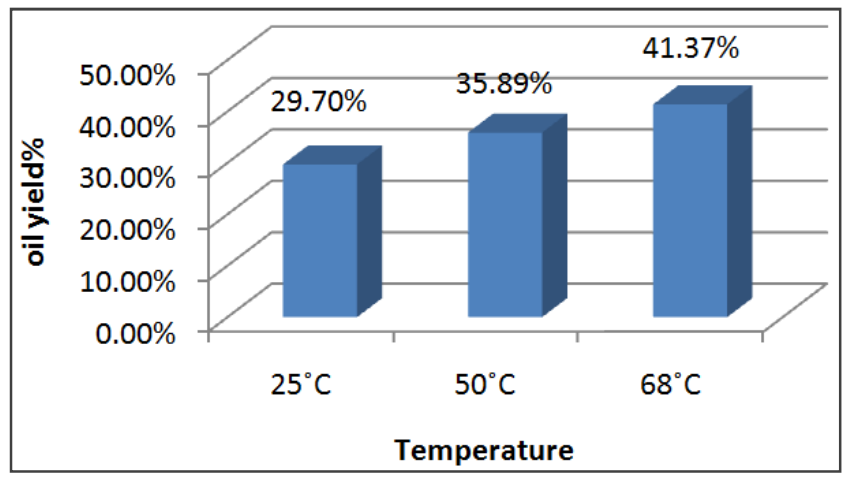

Fig. 3. The effect of extraction temperature on amount of extracted oil using hexane as solvent and $0.5 \mathrm{~cm}$ size seeds for $2 \mathrm{~h}$.

\subsection{Effect of Solvent to Solid Ratio}

Fig. 4 shows the amount of extracted oil by n-hexane at 
four different solvent solid ratio 4:1 to $8: 1$, the total amount of extracted oil increased from 29.70 to $41.37 \%$.

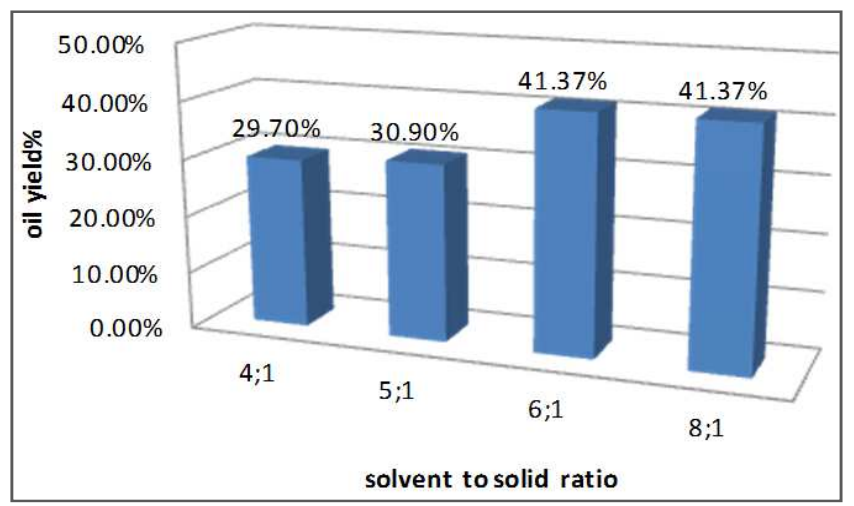

Fig. 4. The effect of solvent to solid ratio on amount of extracted oil using hexane.

\subsection{Effect of Extraction Time}

Fig. 5 shows the total amount of oil extracted from jatropha seed at different reaction times. The amount of extracted oil by $n$-hexane did not change significantly after $6 \mathrm{hr}$. Most of oil is extracted is achieved after $8 \mathrm{hr}$ with $45 \%$.

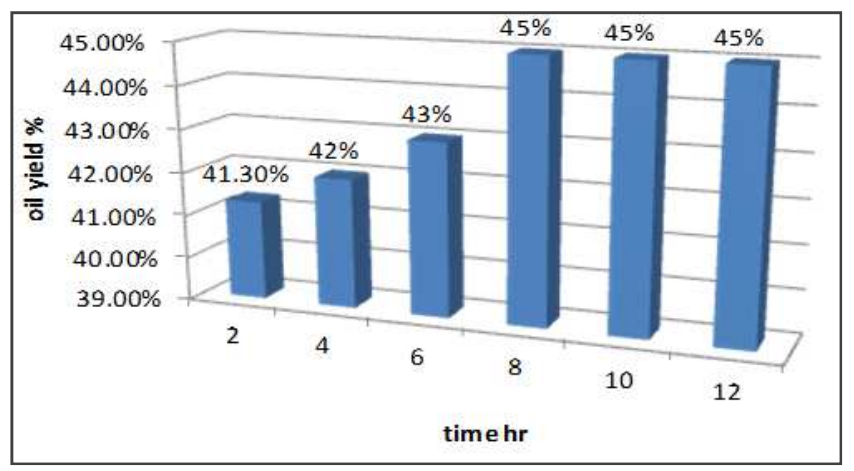

Fig. 5. The effect of time on amount of extracted oil using hexane.

\subsection{Kinetics and Thermodynamics of Extraction}

\subsubsection{Effect of Temperature and Time on Kinetic Study}

Kinetics of extraction of Jatropha oil: The kinetics of oil extraction from Jatropha seeds was studied at different temperatures as shown in table 1 and Fig. 6 the experiments were carried out under optimum reaction conditions using hexane as solvent and $0.5 \mathrm{~cm}$ particle size meal. In kinetic study increasing the extraction temperature, the optimum extraction duration can be reduced as reaction occurs faster. The final concentration also increases with temperatures due to the thermodynamic effect of temperature on solubilization of oil inside the solid. The extraction rate is fast at the beginning of the extraction but gets slow gradually. The reason is that when the meal is exposed to the fresh solvent, the free oil on the surface of seeds is solubilized and oil gets extracted quickly inducing a fast increase in the extraction rate. Furthermore, since the oil concentration is low in the solvent at the beginning of the extraction process, the oil diffuses quickly from the meal to the liquid phase due to the mass transfer effect. As the time passing by, the concentration of oil increases in the solvent resulting in a decrease in the diffusion rate. When the maximum amount of extractable oil is obtained, the oil yield level remains invariable even by extending the reaction time.

A reaction rate equation for oil extraction from Jatropha (equation 2). Since the percent oil yield increased in the course of time, the terms $\mathrm{dY} / \mathrm{dt}$ have a positive sign [9].Using the values in table 1 and applying the Differential Method, plots of $\ln (\mathrm{dY} / \mathrm{dt})$ versus $\ln \mathrm{Y}$ for n-hexane were drawn and were found to be linear according to equation (2). A firstorder kinetics was found from the values of $\mathrm{n}$ obtained, with average $\mathrm{R} 2=0.93$, from the slopes of the straight lines in Fig. 7 , and the reaction rate constants $(\mathrm{K})$ were calculated from the slopes of each curve (table2).

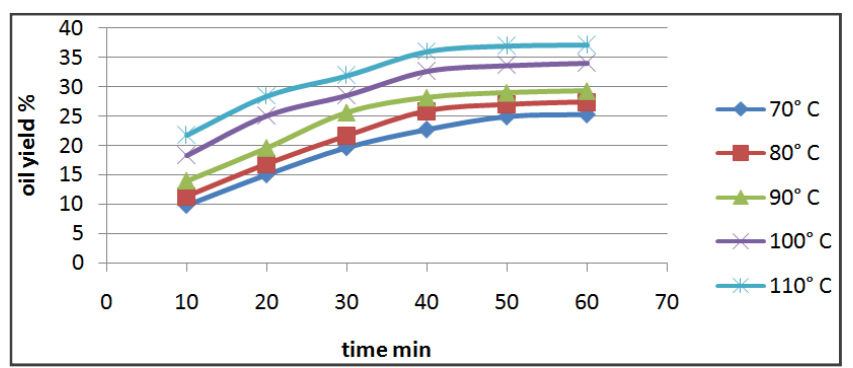

Fig. 6. Amount of extracted oil versus time at different temperatures in solid liquid extraction of Jatropha seeds using hexane as solvent.

Table 1. Amount of extracted oil versus time at different temperatures of Jatropha seeds using hexane as solvent.

\begin{tabular}{|c|c|c|c|c|c|c|c|c|c|c|}
\hline $\begin{array}{l}\text { Time } \\
(\mathrm{min})\end{array}$ & $\begin{array}{l}\text { Wt. of oil } \\
\text { at }\left(70^{\circ} \mathrm{C}\right)\end{array}$ & Yield \% & $\begin{array}{l}\text { Wt. of oil } \\
\text { at }\left(80^{\circ} \mathrm{C}\right)\end{array}$ & Yield \% & $\begin{array}{l}\text { Wt. of oil } \\
\text { at }\left(90^{\circ} \mathrm{C}\right)\end{array}$ & Yield \% & $\begin{array}{l}\text { Wt. of oil at } \\
\left(100^{\circ} \mathrm{C}\right)\end{array}$ & Yield \% & $\begin{array}{l}\text { Wt. of oil at } \\
\left(110^{\circ} \mathrm{C}\right)\end{array}$ & Yield \% \\
\hline 10 & 4.44 & 9.86 & 5.1 & 11.33 & 6.28 & 13.955 & 8.3 & 18.3 & 9.8 & 21.778 \\
\hline 20 & 6.77 & 15.04 & 7.582 & 16.848 & 8.81 & 19.577 & 11.29 & 25.08 & 12.79 & 28.422 \\
\hline 30 & 8.84 & 19.64 & 9.74 & 21.64 & 11.53 & 25.622 & 12.85 & 28.55 & 14.35 & 31.888 \\
\hline 40 & 10.2 & 22.667 & 11.64 & 25.866 & 12.68 & 28.177 & 14.7 & 32.666 & 16.2 & 36 \\
\hline 50 & 11.2 & 24.88 & 12.13 & 26.955 & 13.05 & 29 & 15.13 & 33.622 & 16.63 & 36.95 \\
\hline 60 & 11.35 & 25.22 & 12.32 & 27.377 & 13.19 & 29.311 & 15.32 & 34.04 & 16.71 & 37.133 \\
\hline
\end{tabular}




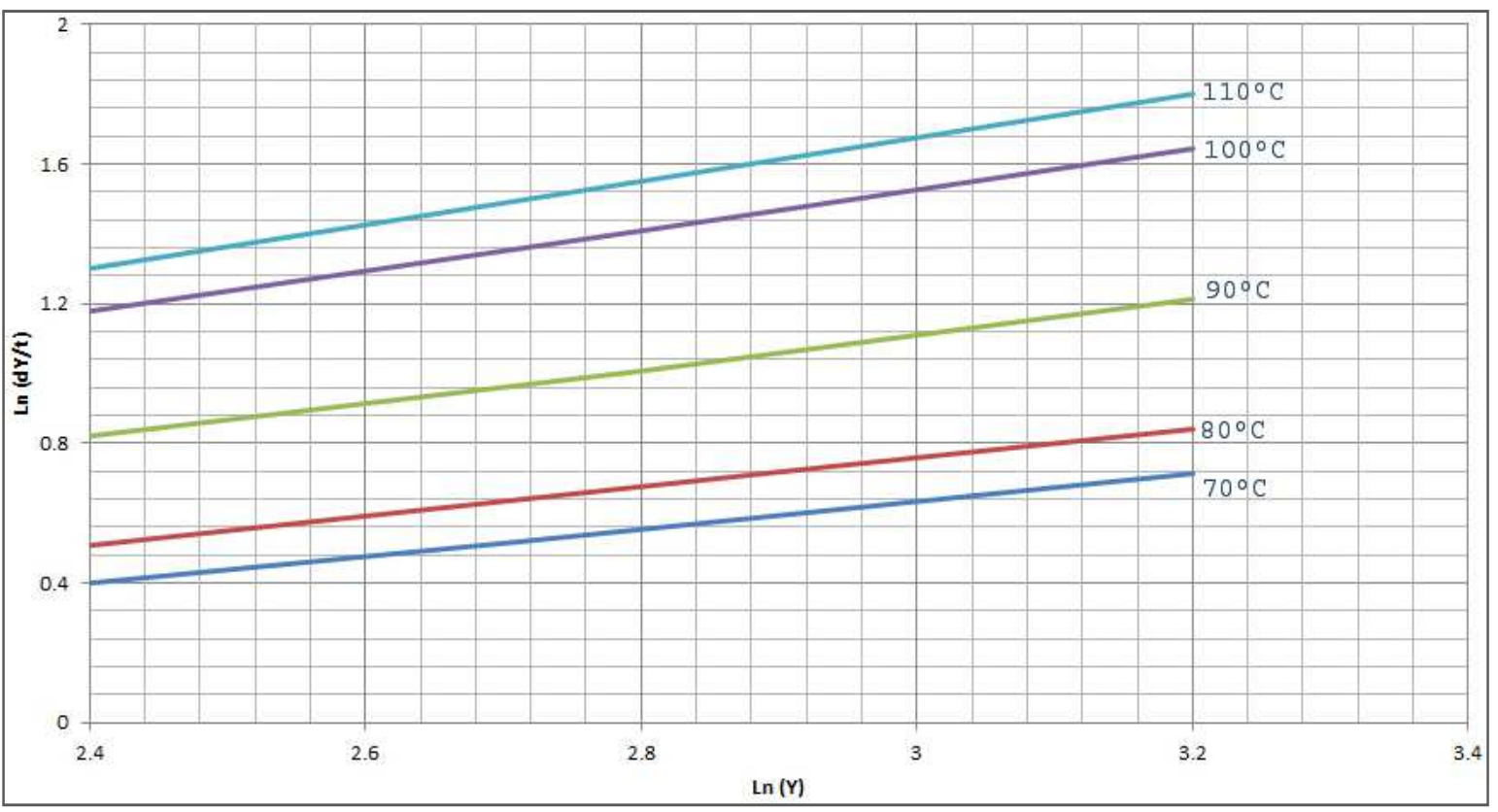

Fig. 7. A Plot of $[\ln (d Y / d t)]$ versus $[\ln Y]$ at Different Temperatures for the Extraction with Containing $n$-Hexane.

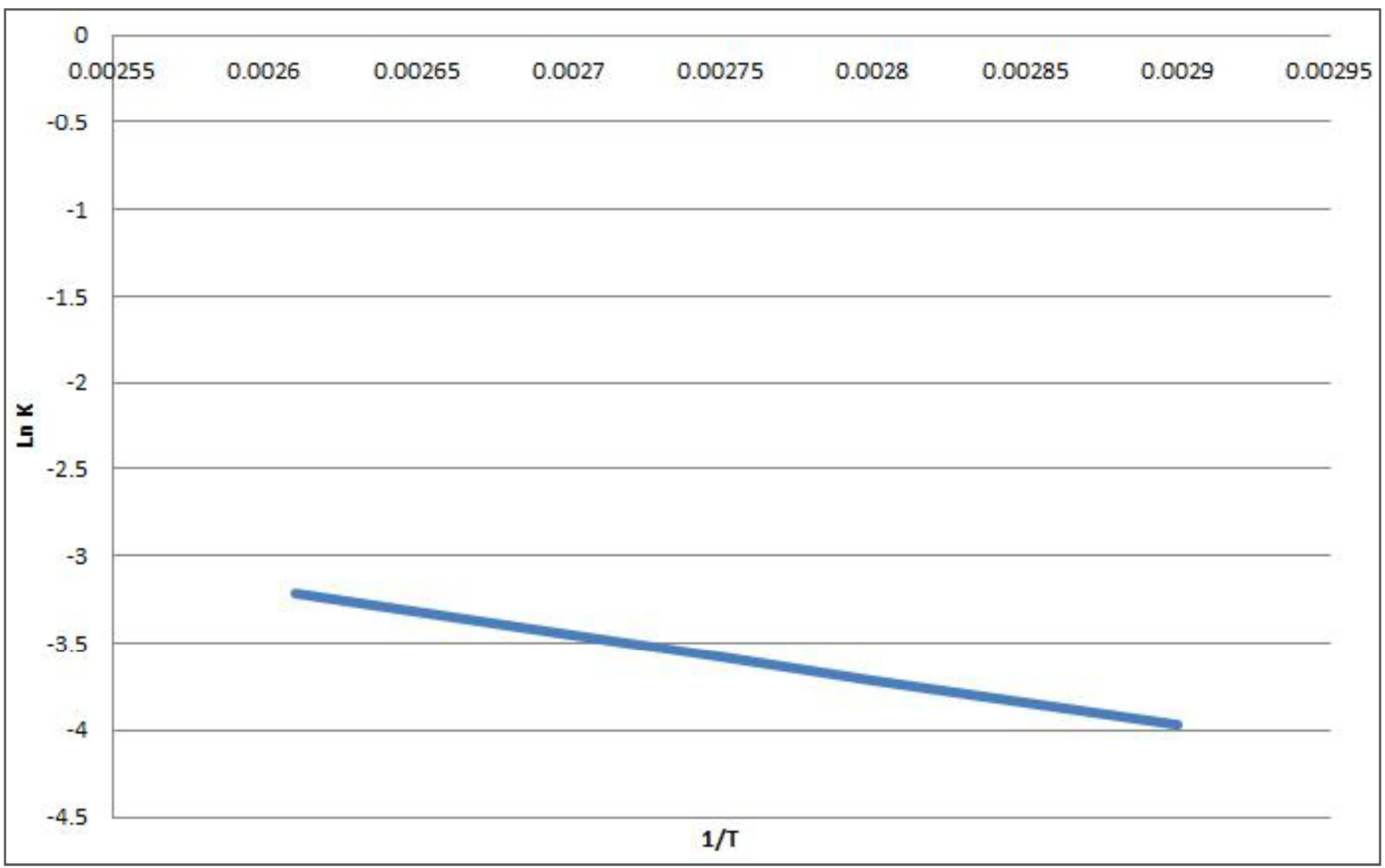

Fig. 8. A Plot of [ln k] versus [1/T] for jatropha oil Extraction with n-Hexane.

Table 2. Show values of rate constants $(K)$ and [ln k] versus [1/T] for jatropha oil Extraction with $n$-Hexane.

\begin{tabular}{lllll}
\hline $\begin{array}{l}\text { Temperature } \\
\left({ }^{\circ} \mathbf{C}\right)\end{array}$ & $\begin{array}{l}\text { Temperature } \\
\left({ }^{\circ} \mathbf{k}\right)\end{array}$ & K(slope) & $\begin{array}{l}\mathbf{1} / \text { temp. } \\
\left({ }^{\circ} \mathbf{k}^{-1}\right)\end{array}$ & $\mathbf{I n K}$ \\
\hline 70 & 343 & 0.019 & 0.0029 & -3.963 \\
80 & 353 & 0.024 & 0.0028 & -3.729 \\
90 & 363 & 0.03 & 0.00275 & -3.5 \\
100 & 373 & 0.036 & 0.00268 & -3.324 \\
110 & 383 & 0.04 & 0.00261 & -3.21 \\
\hline
\end{tabular}

Table 3. Show values of [ln k] versus [1/T] for Jatropha oil Extraction with n-Hexane.

\begin{tabular}{lllll}
\hline $\begin{array}{l}\text { Temperature } \\
\left({ }^{\circ} \mathbf{C}\right)\end{array}$ & $\begin{array}{l}\text { Temperature } \\
\left({ }^{\circ} \mathbf{k}\right)\end{array}$ & $\begin{array}{l}\mathbf{K}=\mathbf{Y t} / \mathbf{Y u} \text { at } \mathbf{6 0} \\
\mathbf{m i n}\end{array}$ & $\begin{array}{l}\mathbf{1 / t e m p .} \\
\left({ }^{\circ} \mathbf{k}^{-\mathbf{1}}\right)\end{array}$ & $\mathbf{l n K}$ \\
\hline 70 & 343 & 0.536 & 0.0029 & -0.62 \\
80 & 353 & 0.5817 & 0.0028 & -0.54 \\
90 & 363 & 0.6228 & 0.00275 & -0.47 \\
100 & 373 & 0.723 & 0.00268 & -0.32 \\
110 & 383 & 0.789 & 0.00261 & -0.23 \\
\hline
\end{tabular}




\subsubsection{Calculation of Activation Energy}

From table 2 and equation 6 Fig. 8 was performed were the activation energy and the Arrhenius constant calculated. These were Ea. $=33.25 \mathrm{~kJ} / \mathrm{mol}$ and $\mathrm{A}=33.25 \mathrm{~s}^{-1}$, respectively. Tables 2 show values of [ln $\mathrm{k}]$ versus $[1 / \mathrm{T}]$ for Jatropha oil extraction with $\mathrm{n}-\mathrm{Hexane}$.

\subsubsection{Calculation of Thermodynamic Parameters}

Thermodynamic parameters $(\Delta \mathrm{H}, \Delta \mathrm{G}$ and $\Delta \mathrm{S})$ for the extraction of Jatropha oil using $n-$ hexane as solvent can be estimated using equations $(2,4)$.

From table 3 , A plot of $\operatorname{lnK}$ vs. $1 / \mathrm{T}$ at $60 \mathrm{~min}$, gives a straight line whose intercept represents the entropy change of extraction, $\Delta \mathrm{S} / \mathrm{R}$. Thus, the entropy change was calculated to be $\Delta \mathrm{S}=0.1478 \mathrm{~kJ} / \mathrm{mol} . \mathrm{K}^{-1}$ for Jatropha seed oil extraction with $\mathrm{n}$-hexane Fig. 9. Other thermodynamic parameters $(\Delta \mathrm{H}$ and $\Delta G$ ) and the equilibrium constant values for Jatropha seed oil extraction with n-hexane at $60 \mathrm{~min}$, are given in table (4) for each temperature.

According to these results, the positive value of enthalpy indicates that the process is endothermic and requires energy during process. In addition, the positive value of $\Delta \mathrm{G}(\Delta \mathrm{G}>$
0) at $60^{\circ} \mathrm{C}$ indicates that there is a increase in the free energy, that is, the Extraction process of Jatropha oil using $n-$ hexane at $60^{\circ} \mathrm{C}$ is non-spontaneous process, which is in agreement with previous investigations The reaction system initially consists of the ground Jatropha seed and n-hexane, whereas the oil molecules are extracted from the Jatropha seeds during the extraction process, and therefore, the entropy of the mixture increases in the course of the extraction, that is the positive value of entropy change $(\Delta \mathrm{S}>0)$ at $60^{\circ} \mathrm{C}$ indicates that the process is irreversible, while at temperatures less than $60^{\circ} \mathrm{C}$, the reaction is reversible.

Table 4. The thermodynamic parameters ( $\Delta H$ and $\Delta G)$ for jatropha oil extraction with $n$-hexane.

\begin{tabular}{lll}
\hline Temperature $\left({ }^{\circ} \mathbf{k}\right)$ & $\boldsymbol{\Delta H}(\mathbf{k j} / \mathbf{m o l e})$. & $\Delta \mathbf{G}(\mathbf{k j} / \mathbf{m o l e})$. \\
\hline 343 & 52.487 & 1.778 \\
353 & 53.777 & 1.59 \\
363 & 55.095 & 1.429 \\
373 & 56.15 & 1.005 \\
383 & 57.377 & 0.754 \\
\hline
\end{tabular}

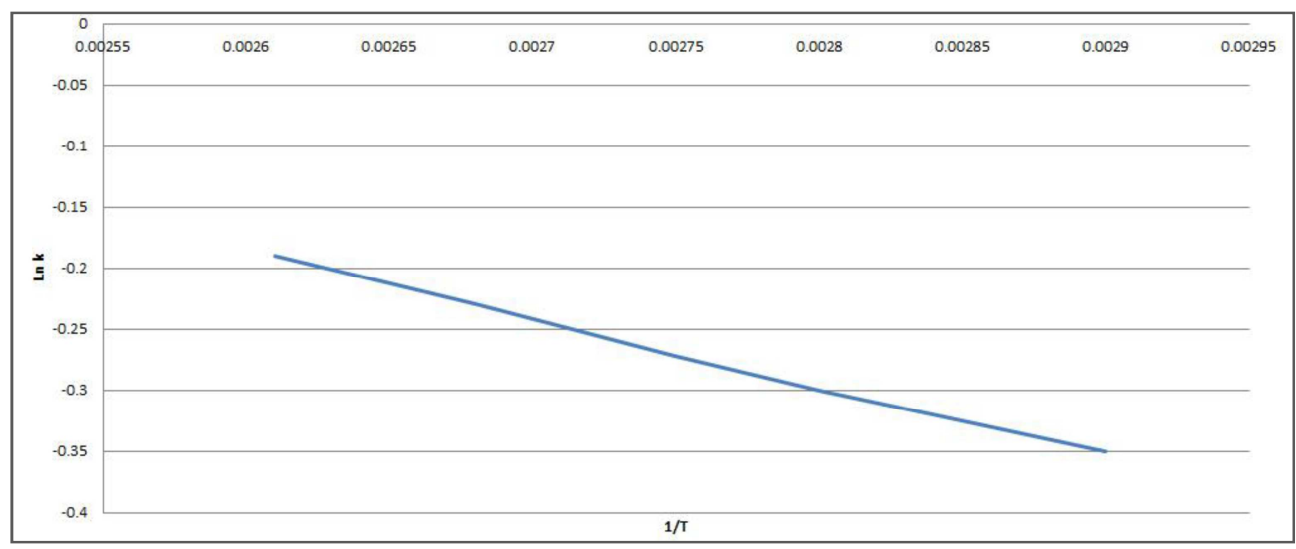

Fig. 9. A Plot of [ln k] versus [1/T] for Jatropha oil Extraction with $n$-Hexane for 60min.

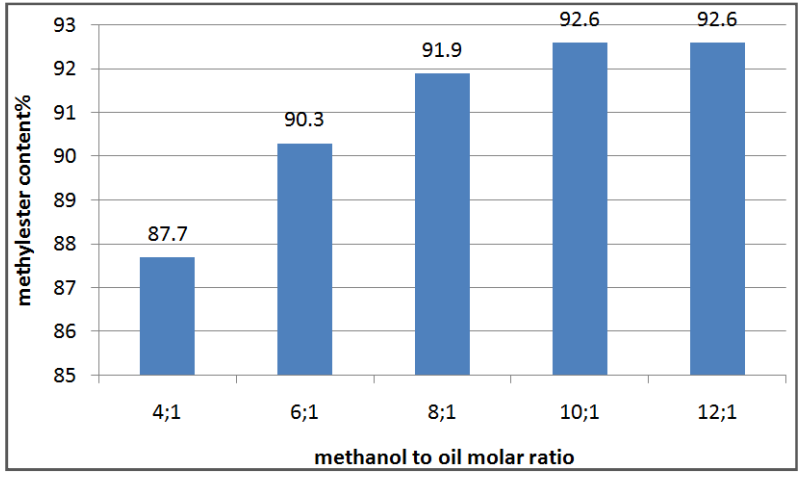

Fig. 10. Effects of methanol-to-oil molar ratio in methanolysis.

\subsection{Production Process of Transesterification}

\subsubsection{Effects of Methanol-to-Oil Molar Ratio in Methanolysis}

It was observed that the alkali-catalyzed methanolysis could occur quickly and the reaction time required for the completion of the reaction. The methyl ester content increased as the methanol-to-oil molar ratio increased. The methyl ester content for a methanol-to-oil molar ratio of 10:1 was $92.5 \% \mathrm{w} / \mathrm{w}$ after 40 minutes, whereas the content was obtained with a methanol to oil molar ratio of $4: 1,6: 1$ and 8 : 1 were $87.7,90.3$ and 91.9 respectively(Fig. 10).

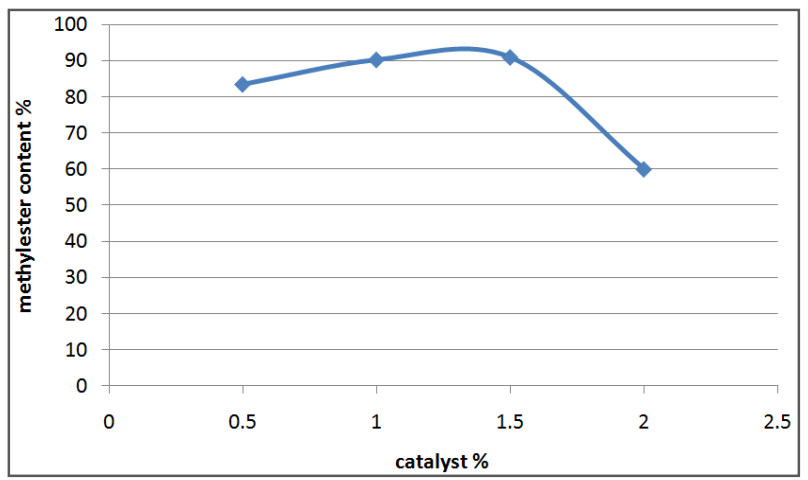

Fig. 11. Effect of Catalyst Concentrations in methanolysis. 


\subsubsection{Effect of Catalyst Concentrations in Methanolysis}

The results show that the catalyst concentration had a significant effect on alkali-catalyzed methanolysis. The methyl ester content increased with higher catalyst concentrations as Fig. 11. However, with the catalyst concentration increased to $2 \% \mathrm{w} / \mathrm{w}$ of oil, it was not possible to achieve methanolysis due to the formation of soap and a gelatinous layer in the reaction mixture. In addition, it was found that the reaction scarcely occurred with a catalyst concentration of $0.5 \% \mathrm{w} / \mathrm{w}$ of oil. At a catalyst concentration of $1 \% \mathrm{w} / \mathrm{w}$ of oil, the methyl ester content achieved $90.3 \%$ w/w after 40 minutes, Although, the catalyst concentration of $1.5 \% \mathrm{w} / \mathrm{w}$ of oil provided a higher methyl ester content than that of $1 \% \mathrm{w} / \mathrm{w}$ of oil for all reaction times, such a concentration should be avoided for two significant reasons: the cost of the additional $\mathrm{NaOH}$, and the cost of removing the residual catalyst in the methyl ester layer. Moreover, the methyl ester layer obtained from using this catalyst concentration has to be washed with hot distilled water several times in the water washing step, so there is a possibility of losing some biodiesel product to emulsion formation. For these reasons, $1 \% \mathrm{w} / \mathrm{w}$ of oil was considered to be the optimum catalyst concentration.

\subsubsection{Effect of Temperature in Methanolysis}

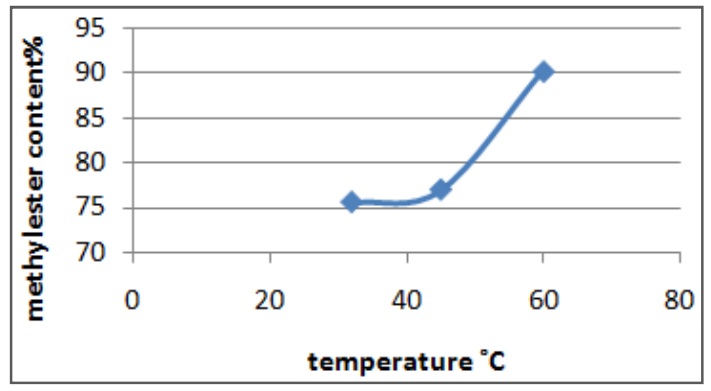

Fig. 12. Effect of temperature in methanolysis.

The operating conditions were fixed at a methanol-to-oil molar ratio of 10:1 and a catalyst concentration of $1 \% \mathrm{w} / \mathrm{w}$ of oil. The results indicate that methanolysis could occur at room temperature $\left(32^{\circ} \mathrm{C}\right)$, but it would be incomplete, even if the reaction time were extended to 40 minutes. For the same reaction time, the methyl ester content increased with temperature. The increase in the methyl ester content might have been due to the viscosity of the oil decreasing with an elevation of reaction temperature, which resulted in an increase in the solubility of the oil in the methanol, leading to an improvement in the contact between the oil and the methanol Hence, the reaction was faster at a higher temperature. The same methyl ester content was achieved at a lower temperature as well, but the reaction time had to be increased. The methanolysis proceeded to completion in 40 minutes at $60^{\circ} \mathrm{C}$, (Fig 12) and the methyl ester content of $90 \% \mathrm{w} / \mathrm{w}$ Hence, $60^{\circ} \mathrm{C}$ was selected as the optimum reaction temperature.

\subsubsection{Effect of Time in Methanolysis}

The operating conditions were fixed at a methanol-to-oil molar ratio of 10:1 and12:1 with catalyst concentration of $1 \%$ $\mathrm{w} / \mathrm{w}$ of oil, and the temperature $60^{\circ} \mathrm{C}$ but the time variable from 10 to 70 min the methyl ester content increased with reaction time increase. The methanolysis proceeded to completion in 60 minutes at $60^{\circ} \mathrm{C}$, and the methyl ester content of $91 \% \mathrm{w} / \mathrm{w}$ as in Fig. 13

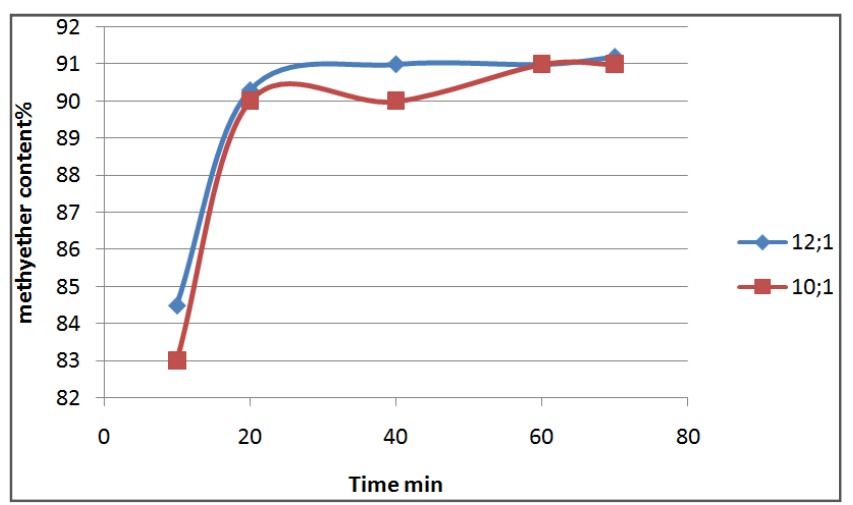

Fig. 13. Effect of time in methanolysis.

Table 5. Jatropha oil composition.

\begin{tabular}{ll}
\hline Fatty acid & Composition (wt \%) \\
\hline Palmitic & 18.22 \\
Stearic & 5.14 \\
Oleic & 28.46 \\
Linolenic & 48.18 \\
Average M.wt & 874 \\
\hline
\end{tabular}

Table 6. Characterization of the extracted Jatropha seed oil.

\begin{tabular}{ll}
\hline Chemical analysis & Value \\
\hline Acid value & $2.3 \%$ \\
Saponification value & $200 \mathrm{mg} / \mathrm{gm}$ \\
Moisture content & $0.912 \%$ \\
Fatty acid percentage & $0.9 \%$ \\
Specific gravity & 0.912 \\
viscosity & $71 \mathrm{C} . P$ \\
\hline
\end{tabular}

Table 7. The comparison between biodiesel, Jatropha, diesel and blend biodiesel.

\begin{tabular}{llllll}
\hline Tests & Biodiesel of Jatropha oil & Diesel & B10 & B15 & B25 \\
\hline FFA & - & - & - & - & - \\
Specific gravity $15^{\circ} \mathrm{C}$ & 0.8582 & 0.8246 & 0.8319 & 0.8351 & 0.8421 \\
Flash point,${ }^{\circ} \mathrm{C}$ & 162 & 59 & 61 & 64 & 67 \\
Pour point,${ }^{\circ} \mathrm{C}$ & 0 & -3 & -3 & -3 & -3 \\
Viscosity $25^{\circ} \mathrm{C}$ & 42 & 33 & 36 & 37 & 40 \\
Calorific value $\mathrm{J} / \mathrm{Kg}$ & 37.2 & 42.6 & 45.31 & 42.15 & 41.03 \\
Cetane number & 53 & 46 & 47 & 48 & 49 \\
Density gm/cm3 & 0.95 & 0.87 & 0.89 & 0.9 & $38-46$ \\
\hline
\end{tabular}




\subsection{Characterization of the Extracted Jatropha Seed Oil}

Jatropha oil composition was determined and reported in table 5, according to the chemical composition of jatropha oil the average molecular weight used in calculation is considered to be $874 \mathrm{gm} / \mathrm{mol}$

Experimental results showed that Jatropha oil seeds have FFA content $0.9 \%$. The FFA and moisture contents have significant effects on the transesterification of glycerides with alcohol using catalyst . The high FFA content $(>1 \% \mathrm{w} / \mathrm{w})$ will happen to soap formation and the separation of products will be exceedingly difficult and as a result it has low yield of biodiesel product. But the raw Jatropha oil contain a low percentage of FFA so that the oil can directly be utilized in a Transesterification [2] as in table 6 .

\subsection{Characterization of the Biodiesel from Jatropha Oil}

Tests were done on the sample prepared at optimum condition table7 shows the physical characteristics of biodiesel produced at $60^{\circ} \mathrm{C}, 60 \mathrm{~min}$ and at methanol oil molar ratio $10: 1$ and $1 \%$ catalyst concentration.

The biodiesel is used as a fuel in the form a blend with the diesel fuel (fossil fuel) .the biodiesel can be blended in any percentage. Biodiesel blends 10, 15 and 25\%. For example blend (B10) refers 10 volume percent of biodiesel is present also table 7 shows the comparison between biodiesel, Jatropha, diesel and blend biodiesel

The following results shown in table 7 are obtained in comparison between biodiesel and diesel the specific gravity reduced after transesterification, viscosity from 71 to $36 \mathrm{cp}$ than increase slightly with blend with diesel. which is important character for engine operation (viscous fuel makes the engine life longer[6])

Flash point is important temperature specified for safety during transport, storage and handling. Flash point of jatropha biodiesel was found to be $162^{\circ} \mathrm{C}$, flash point of jatropha oil decrease after transesterification and blends show that its volatile characteristics had improved and it is also safe to handle where it reach $61^{\circ} \mathrm{C}$ with $10 \%$ blend and increase for $15 \%$ blend and $25 \%$ blend. Fuels with flash point above $67^{\circ} \mathrm{C}$ are considered as safe fuel. The pour point for jatropha oil is $6^{\circ} \mathrm{C}$ but for biodiesel it is $0^{\circ} \mathrm{C}$ and for blends become $-3^{\circ} \mathrm{C}$. In general high pour point often limits their use as fuel for diesel engine in cold climatic conditions. When the ambient temperature is below the pour point the oil wax precipitate in oil and they loose their flow characteristics, wax can block the filters and fuel supply line under these conditions fuel cannot be pumped through the injector. In Egypt, ambient temperature is higher than pour point of jatropha oil and biodiesel also blends. The most important character of fuel is calorific value $(\mathrm{CV})$ a very successful results are obtained where $\mathrm{CV}$ of biodiesel $=37.2 \mathrm{~J} / \mathrm{kg}$ while $\mathrm{CV}$ of diesel $=42.6 \mathrm{~J} / \mathrm{kg}$ and it is increased by blending up to $45 \mathrm{~J} / \mathrm{kg}$.

\section{Conclusion}

The following conclusion was drawn from this research work:

The optimum conditions for oil extraction were obtained at temperature at $68^{\circ} \mathrm{C}$, extraction time $8 \mathrm{hr}$ with solvent to seed ratio 6: $1 \mathrm{v} / \mathrm{wt}$ with particle size $0.5 \mathrm{~cm}$ where hexane give better oil yield compared to isopropanol and petroleum ether

The kinetics of extraction was developed based on first order extraction mechanism where the experiment data agrees will with first order model.

Study the optimum conditions for jatropha biodiesel production which are methanol: oil molar ratio 10: 1, catalyst concentration $1 \%(\mathrm{w} / \mathrm{w})$ reaction temperature $60^{\circ} \mathrm{C}$ and reaction time $60 \mathrm{~min}$.

Study the general properties of jatropha oil and biodiesel using alkali catalyzed methanolysis process

Blends the biodiesel with 10,15 , and $25 \%$ with diesel and study the thermo physical properties and compare between them.

\section{Acknowledgements}

I would like to thank students of high institute of engineering chemical engineering department class of $2012 / 2013$ for their work and sharing also I would like to thank the chief of the high institute of engineering chemical engineering department.

\section{References}

[1] Ali E., and Tay C. (2013) Characterization of Biodiesel produced from palm oil via base catalyzed transesterification. procedia engineering 53: 7-12

[2] Berchmans, H.J. and Hirata. S (2008) Biodiesel production from crude jatropha curcas L. seed oil with a high content of free fatty acids. J. Bioresource Technology 99: 1716-1721. http://www.Scenice direct.com.

[3] Tiwari, A.K., Kumar, A. and Raheman, H (2007) biodiesel production from jatropha (jatropha curcas oil) with high free fatty acid: An optimized process. J. Biomass \& Bioenenergy 31: 569-575.

[4] Yusuf, N., Kamarudin, S.k., Yaakub, Z., (2011) overview on the current trends in biodiesel production, Energy conversion and management 52, p. 2741.

[5] Tyagi, S.O., Atray, N., Kumar, B., \& Abhadatta, A (2010) Characterization and development of standards for biodieselAreview J. Metrology society of India.production, 197-218.

[6] Saxena, P., Jawale, S., Joshipura, M (2013) Review on prediction of properties of biodiesel and blends of biodiesel. procedia engineering 51: 395-402.

[7] Demirbas, A., (2009) program and recent trends in biodiesel fuels, Energy conversion and management 50, p.14. 
[8] Tewfik S. R., Hawash S., Attey N.K., El Diwani G. and Farag I. (2012) Techno-economic appraisal of biodiesel from Jatropha curcas: An Egyptian case study. journal of Agricultural sciences and technologyB2 287-297.

[9] Sayyar, S., Abidin, Z. Z., Yunus, R. and Muhammad, A. (2009) Extraction of Oil from Jatropha Seeds-Optimization and Kinetics American Journal of Applied Sciences 6 (7): 1390-1395.

[10] Amin Sh. K., Hawash S., El Diwani G., and El Rafe S. (2010) Kinetics and Thermodynamics of Oil Extraction from Jatropha Curcas in Aqueous Acidic Hexane Solutions. J. American Science 6: 11 .

[11] Nwabanne, J. T. (2012) Kinetics and Thermodynamics Study of Oil Extraction from Fluted Pumpkin Seed international journal of multidisciplinary science and engineering 3.6.
[12] Topallar, H. and Geçel, Ü. (2000). "Kinetics and ThermoDynamics of Oil Extraction from Sunflowers Seeds in the Presence of Aqueous Acidic Hexane Solutions". Turk J. Chem., 24, 247-253.

[13] Hawash, S., Kamal, N. and El-Diwani, G.. (2008) "Egyptian Jatropha Oil Extraction for Biodiesel Production". AFINIDAD, 65 (538).

[14] Levenspiel, O. (2003)"Chemical Reaction Engineering". Third edition, John Wily and Sons Inc., New York.

[15] Mohammad- Dabo, A., Ahmed M.S., Hamza, A.., Muazu K. and Aliyu A. (2012) Cosolvent transesterification of Jatropha curcas seed oil. journal of petroleum technology and alternative fuel vol.3(4) pp42-51.

[16] Azhari, F., Yunus R., Ghazi, M., and Yaw, S. (2008) reduction of free fatty acid in crude jatropha curcas oil via an esterification process. international journal of engineering and technology vol.5 p 92-98. 